\title{
Callender's New High-Voltage Research Laboratories
}

\begin{abstract}
7 HE new high-voltage research laboratories of Callender's Cable and Construction Co., Ltd., are being opened on June 22 by Lord Rutherford, before a distinguished company, which will include the Council of the Institution of Electrical Engineers, by special invitation of the president, Mr. P. V. Hunter. The laboratories occupy the buildings of the old Kensington and Notting Hill Gate Power Station, at 38 Wood Lane, W.12. The large space and headroom provided by these buildings have made them especially suitable for conversion to high-voltage laboratories. Altogether, 30,000 sq. ft. of ground floor space have been equipped as research laboratories, together with associated stores and workshop. The laboratories have been organised and equipped in a manner which will enable research work to be carried out in any field associated with the transmission of electrical power.
\end{abstract}

The main high-voltage equipment consists of two transformers by Ferranti, each for $500 \mathrm{kva}$. continuous output at 500,000 volts. It is believed that these are the largest transformers of this voltage available at present in the industry. The large size of the transformers has been made necessary by the large capacitance current which is required for cable testing at high voltage. These two transformers are situated in adjoining laboratories which are $130 \mathrm{ft}$. long, and $45 \mathrm{ft}$. and $28 \mathrm{ft}$. wide respectively. One of these transformers has been mounted on porcelain insulators, so that the tank of the transformer can be raised to a voltage of $500 \mathrm{kv}$. to earth. In addition, a large opening in the wall dividing the two laboratories enables the two transformers to be connected in parallel or in cascade, thus providing $1,000 \mathrm{kva}$. at either $1,000 \mathrm{kv}$. or $500 \mathrm{kv}$. The lay-out of these two laboratories represents a distinct departure from the usual practice in high-voltage laboratories. The two transformers have been located in the middle of the laboratories. Each transformer thus commands two testing areas, one on each side. In this way, it is possible for preparation work to be pressed forward in one area while the transformer is testing in the other area, with a complete absence of risk to the personnel concerned. It is a general experience in high-voltage laboratories that the preparation time far outweighs the time spent in actual testing. It has been found, however, that the above arrangement of the transformers makes for efficient use of the testing equipment.

The question of supply to the transformers received very careful consideration. It was required that high voltage should be available at any frequency between 25 cycles and 75 cycles per second. At the same time, the very sharp response curve of the vibration galvanometer used in making dielectric loss angle measurements made it essential that, when testing at any given frequency, the alternator speed should be held absolutely constant with variation of load or with variation of such factors as the supply voltage. It was not found possible to obtain sufficiently constant speed regulation with the usual arrangement of a Ward-Lennard set. The arrangement finally selected consists of a 3-phase synchronous motor, driving a 3,000 volt single phase alternator through a fluid gear box, which provides a continuously variable gear ratio over the above range. All this equipment is by Haslam and Newton, Ltd., of Derby. From the testing which has so far been carried out, it appears that this equipment is likely to prove entirely satisfactory.

The cablelife testinglaboratory contains transformer equipment by British Thomson-Houston Co., Ltd., which enables long lengths of buried cable for $66 \mathrm{kv}$. and $132 \mathrm{kv}$. systems to be tested at twice working voltage, under conditions which simulate service conditions. The two high-voltage transformers are for $500 \mathrm{kva}$. and $1,000 \mathrm{kva}$. respectively. These transformers are supplied by 3,000 volt single phase alternators, direct coupled to 3-phase synchronous motors. In addition to the high-voltage transformers, two loading current transformers supply a total of 1,500 amp., the high-current windings being insulated from earth for $170 \mathrm{kv}$. This enables cable heating current to be superimposed on the cable conductor without interrupting the high voltage, and in this way the cables are passed through periodic heat cycles. An unusual feature of this transformer equipment is that double electrostatic screens have been provided between the primary and secondary windings for the purpose of enabling accurate dielectric loss angle measurements to be carried out on cables which are buried, and in which, therefore, the cable sheaths are necessarily earthed. The cables are buried in runs of about 200 yards in land adjoining the laboratories which consists of made-up soil representative of normal London conditions.

In addition, the laboratory possesses a large amount of smaller transformer equipment for voltages up to $120 \mathrm{kv}$. which is used for the development of cable accessories such as joints and sealing ends, and for general investigations into the theory and mechanism of breakdown of high-voltage cable dielectric.

Smaller laboratories are provided for dielectrics, chemistry and physics, and these provide all facilities for a large number of investigations which arise out of the main research programmes on the high-voltage cables themselves.

\section{Conversion of Municipal and Village Wastes into Humus}

LTHOUGH at the moment many agricultural
regions are more concerned with the profitable
marketing of their surplus produce than with methods
designed to increase crop-production, nevertheless
there are important exceptions to this general rule.
In India, for example, the food supply of the villages,
some 500,000 in number, is markedly deficient in
amount, while the low quality is considered by many medical authorities on the spot to be one of the chief factors responsible for the poor general health and want of resistance to disease on the part of the population. In other parts of the tropics the maintenance of the food supply of the people is always one of the major anxieties of the authorities. In such circumstances any practicable method, by which the local food crops can be improved and to 
some extent ensured, will at once command attention. Such a method has recently been worked out at the Institute of Plant Industry at Indore in Central India. The earlier results were published by Messrs. Howard and Wad in 1931 as "The Waste Products of Agriculture" which was reviewed in NATURE of November 21, 1931. In the February number of the Indian Medical Gazette of the present year, Messrs. Jackson and Wad have successfully applied the Indore method of manufacturing humus from agricultural wastes to the conversion of night soil and town refuse into a valuable compost*.

During 1932 and 1933 town wastes have been converted into humus at three centres-(1) Indore City, where the waste products of 60,000 inhabitants were dealt with; (2) the Indore Residency enclave, with a population of 4,000 ; and (3) the lines of the Malwa Bhil Corps where the numbers are about 1,000. These three centres are representative of a large municipality, a small town or military cantonment and an ordinary Indian village. The arrangements for the conversion are very simple and inexpensive. The humus factory consists of : (1) a metalled service road, $20 \mathrm{ft}$. wide; (2) a charging trench on either side, $2 \mathrm{ft}$. deep and $15 \mathrm{ft}$. wide, the floor and sides of which are preferably made smooth and impermeable so as to prevent the breeding of flies; and (3) metalled storage areas, at least $20 \mathrm{ft}$. wide, on which the ripe compost can be piled in heaps until it is sold. The manufacture of compost, which takes about a month, consists in the proper arrangement and moistening of the raw materials-town and village refuse and night soil-in the charging trench, followed by the turning of the charge three

* Institute of Plant Industry, Indore, Central India. Bulletin No. 1: The Sanitary Disposal and Agricultural Utilization of Habitation Wastes by the Indore Process. By F. K. Jackson and Y. D. Wad ; with Notes on the Sanitary Aspect by Lieut.-Col. J. R. J. Tyrrell and Lieut.-Col. M. A. Nicholson. Pp. $26+3$ plates. (Indore.) 8 annas. times at suitable intervals. An intense fermentation accompanied by a rapid rise in temperature to above $50^{\circ} \mathrm{C}$. at once sets in. The copious aeration which is ensured by the proper admixture of the materials leads to the rapid oxidation of the organic matter and to the destruction of all noxious odours, while the high temperature destroys the fly maggots and probably the ova of helminths and the spores of pathogenic bacteria as well.

The chemical composition of the final product is very satisfactory. The percentage of nitrogen on a dry basis is nearly 1 per cent while the percentages of phosphorus, potash and lime are ample. The results obtained with such crops as sugar-cane, wheat, cotton, lucerne and vegetables are such that the product finds a ready sale. The sale proceeds are considerably greater than the cost of manufacture and therefore a substantial profit is obtained, instead of the usual loss. During the last year at Indore City, for example, a net profit of Rs. 3,085 was obtained. Under the old method of disposal at this centre the net deficit was Rs. 4,535. From the point of view of sanitation and public health, two of the medical officers in Central India-Colonels Tyrrell and Nicholson-record their opinion on the process. Both consider that the method is likely to prove the most satisfactory system so far employed for the disposal of municipal wastes.

The Indore results are already being taken up at other centres in India. The process has been adopted by the Military Cantonment at Neemuch, and at Okara, a small town of 9,000 inhabitants in the Punjab. At the suggestion of Sir Malcolm Hailey, the Governor of the United Provinces, the Public Health Department has decided to experiment with the method, while the Public Works Department of New Delhi is examining the process with the view of applying it as a solution of their very serious refuse disposal problem.

\section{Measurement of Noise}

$\mathrm{I}^{\mathrm{N}}$ a paper read to the Institution of Electrical Engineers on March 8, Messrs. B. G. Churcher, A. J. King and H. Davies read a paper on experiments on the measurement of noise, with special reference to engineering noise problems (see also NATURE, 132, 350, Sept. 2, 1933).

The authors point out that the old conception that sounds can be classified into music and noise is untenable. For their purposes they define noise as irksome or undesired sound. For example, the sound of a radio set operated in a room to the pleasure of some of the occupants may constitute an irksome noise to others who wish to converse. They discuss the laws governing the threshold of hearing, the relation of the magnitudes of the stimuli at different frequencies which produce equal sensations of loudness and the relation between stimulus and sensation. They define the threshold as the largest sound the complete removal of which is not detected.

In determining the threshold, it is essential that there is no 'background' noise. The range of frequencies covered is $100-6,400$ cycles per second at octave intervals so that measurements were made at seven frequencies. Points determined in this way are sufficiently close to define the threshold curve.

The experiments were carried out in the laboratories of Metropolitan-Vickers Electrical Co., Ltd.
Fifty persons were experimented on and were divided into male and female groups. At 100 cycles per second the female group is $2-3$ decibels less sensitive than the male. At 800 cycles per sec. there is a tendency in both groups for sensitivity to decrease with increasing age, but the female group is now 2-3 decibels more sensitive than the male. At 6,400 cycles per sec. the average sensitivities of the two groups are approximately equal, the three oldest males having a much lower sensitivity than the rest.

The old loudness scale used by the authors and the decibel scale are logarithmic scales of physical stimulus. Doubt is thrown on the correctness of this method of measuring sound sensation. Experience has shown that the rate of increase of loudness with the decibels above the threshold is comparatively small at low intensities and much larger at high intensities. Masking and balancing methods of measuring the noise were experimentally tried and the latter was found much the more satisfactory. A pure tone was taken as the standard sound, as it is easy to specify and reproduce accurately. The procedure is to find the physical magnitude of the standard stimulus which produces a loudness sensa. tion of the same magnitude as that due to the source under observation. The judgment of loudness 